\title{
Co-catalysis in phase transfer catalyzed reactions (a concept paper)
}

\author{
Mieczysław Mąkosza ${ }^{a, *}$ and Michał Fedoryński \\ ${ }^{a}$ Institute of Organic Chemistry, Polish Academy of Sciences, \\ Kasprzaka 44/52, 01-224 Warszawa \\ ${ }^{b}$ Faculty of Chemistry, Warsaw University of Technology,Koszykowa 75, \\ 00-662 Warszawa, Poland \\ E-mail: icho-s@icho.edu.pl

\section{Dedicated to Professor Armand Lattes to celebrate his 50 years of great research and teaching activity}

\begin{abstract}
In this short paper the concept of co-catalysis in phase transfer catalyzed reactions is presented. It was shown that difficulties in the application of phase transfer catalysis for reactions of nonlipophilic inorganic anions such as hydroxide and fluoride anions can be efficiently eliminated when carried out in the presence of co-catalysts.

On selected examples it was shown that numerous processes catalyzed by transition metals are substantially improved when carried out in the two-phase systems in the presence of phase transfer catalysts. Modus operandi of such co-catalytic systems varied depending on the kind of transition metal catalyzed process.
\end{abstract}

Keywords: Phase-transfer catalysis, tetraalkyl ammonium salts, $\beta$-elimination, carbonylation, fluorination, Heck reaction, Suzuki reaction

Phase-transfer catalysis (PTC) is presently a well established, general methodology widely used in laboratory synthesis and chemical industry. The main feature of this methodology is that reactions are carried out in two-phase systems containing organic and aqueous phases of negligible mutual solubility whereas the catalytic process consists in continuous introduction of reacting anionic species into nonpolar organic phase in form of ion pairs with lipophilic cations supplied by the catalyst. Typical PT catalysts are lipophilic tetraalkylammonium (TAA) salts. Further reactions of these species e.g. with appropriate electrophilic partners proceed in the organic phase. ${ }^{1,2}$

There are two general systems in which PT catalyzed reactions are carried out: liquidliquid and liquid-solid, and two major cases: the reacting anionic species are available before the 
reaction in form of sodium or other salts and they shall be continuously generated from the appropriate precursors. In the former case the inorganic liquid or solid phases consist of aqueous solution of salts of desired anions or the salts in solid state being reservoirs of the reacting anions. In the latter case the liquid or solid phases contain basic agents that convert precursors into anionic species that via ion-exchange with the catalyst form lipophilic ion pairs entering the organic phase.

Specific features of PTC are conveniently discussed using reactions of alkyl halides RX with inorganic anions $\mathrm{Y}^{-}$catalyzed by TAA salts $\mathrm{Q}^{+} \mathrm{X}^{-}$as a model process. The process proceeds according to Scheme 1.

$$
\begin{aligned}
& \mathrm{Q}^{+} \mathrm{X}_{\text {org }}^{-}+\mathrm{Na}^{+} \mathrm{Y}_{\text {aq }}^{-} \rightleftharpoons \mathrm{Q}^{+} \mathrm{Y}_{\text {org }}^{-}+\mathrm{Na}^{+} \mathrm{X}_{\text {aq }}^{-} a \\
& \mathrm{R}-\mathrm{X}_{\text {org }}+\mathrm{Q}^{+} \mathrm{Y}_{\text {org }}^{-} \longrightarrow \mathrm{R}-\mathrm{Y}_{\text {org }}+\mathrm{Q}^{+} \mathrm{X}_{\text {org }}^{-} \quad b
\end{aligned}
$$

The key factor deciding on feasibility of the catalytic process is the position of the ionexchange equilibrium $1 a$ that governs the concentration of the reacting anions in the organic phase. This equilibrium is in turn governed by the energy of hydration of the anions $\mathrm{X}^{-}$and $\mathrm{Y}^{-}$. In the row $\mathrm{OH}^{-}, \mathrm{SO}_{4}{ }^{2-}, \mathrm{F}^{-}, \mathrm{Cl}^{-}, \mathrm{CN}^{-}, \mathrm{Br}^{-}, \mathrm{I}^{-}, \mathrm{ClO}_{4}^{-}, \mathrm{SCN}^{-}$etc. always right partner will be preferentially located in the organic phase. Thus a substantial limitation of the PTC is that hydroxide and fluoride anions cannot be efficiently transferred into the organic phase when other, more lipophilic, anions are present in the system.

Co-catalysis. Many catalysts exhibit the desired action or act more efficiently only in the presence of an additional component. Such additional components that make the catalytic process possible, activate the catalyst or modify its action are known as co-catalysts. Co-catalytic processes are widely used in laboratory practice and industrial applications. This phenomenon is frequently observed in the nature, many natural catalysts - enzymes require cocatalysts coenzymes - for proper action.

The phenomenon of cocatalysis in PT catalyzed reactions can be of various nature. The first category of PTC cocatalysis is applicable for reactions of hydrophilic anions, that due to unfavourable ion exchange equilibrium cannot operate efficiently in simple PT catalyzed systems. This category embraces reactions of inorganic anions of low lipophilicity mostly hydroxide and fluoride anions.

There are many examples of reactions catalyzed by transition metals that are carried out in two-phase systems in the presence of PT catalyst. Such reactions catalyzed by transition metals can often proceed independently of PTC in homogeneous or heterogeneous media, however application of PTC to such processes offers substantial advantages. In these processes both catalysts act independently, however when applied together the processes are more efficient. 
To the third category belong cocatalytic processes in which a reagent in the aqueous phase is activated by the association with a catalyst and such anionic associate is transferred to the organic phase by PT catalyst. Upon a reaction in the organic phase the catalyst migrates to the aqueous phase and activates another molecule of the reagent.

Sodium and potassium hydroxides are widely used in organic chemistry mostly as strong base for deprotonation of $\mathrm{CH}, \mathrm{OH}, \mathrm{NH}$ etc. acids to produce carbanions and other anionic species and for $\beta$-elimination processes.

The generation and reactions of carbanions and other organic anions are efficiently executed in two-phase system with concentrated aqueous $\mathrm{NaOH}$ as the source of base in the presence of TAA salts as PT catalysts. Initial mechanistic hypothesis concerning the generation of carbanions in such systems suggested continuous transfer of hydroxide anions in the form of $\mathrm{Q}^{+} \mathrm{OH}^{-}$into the organic phase where they abstract protons from the appropriate precursors. This hypothesis was soon abandoned because of unfavourable ion-exchange equilibrium and consequently negligible transfer of hydroxide anions to the organic phase. It was proposed and subsequently evidenced that abstraction of proton and generation of carbanions and other anionic species proceeds in the interfacial region. The ion exchange with TAA salts in this region produces lipophilic ion pairs with the generated anions that enter the organic phase. Thus, the PT catalyzed generation and reactions of carbanions and other organic anions in the two-phase systems by action of concentrated aqueous $\mathrm{NaOH}$ do not require transfer of hydroxide anions into the organic phase. ${ }^{3}$ On the other hand, PT catalyzed E-2 type $\beta$-elimination requires transfer of $\mathrm{OH}^{-}$anions to the organic phase. In order to explain why generation of carbanions does proceed in the interfacial region whereas E-2 type $\beta$-elimination does not let us discuss simplified model of the interfacial reactions.

Border between two mutually immiscible liquid phases is not a geometrical surface. Due to thermal motion components $\mathrm{A}$ of aqueous phase enter organic phase and vice versa thus one can consider the interfacial region as a kind of third anisotropic phase in which, contrary to bulk phase there is a gradient of concentration of A and B as shown on Fig. 1. 


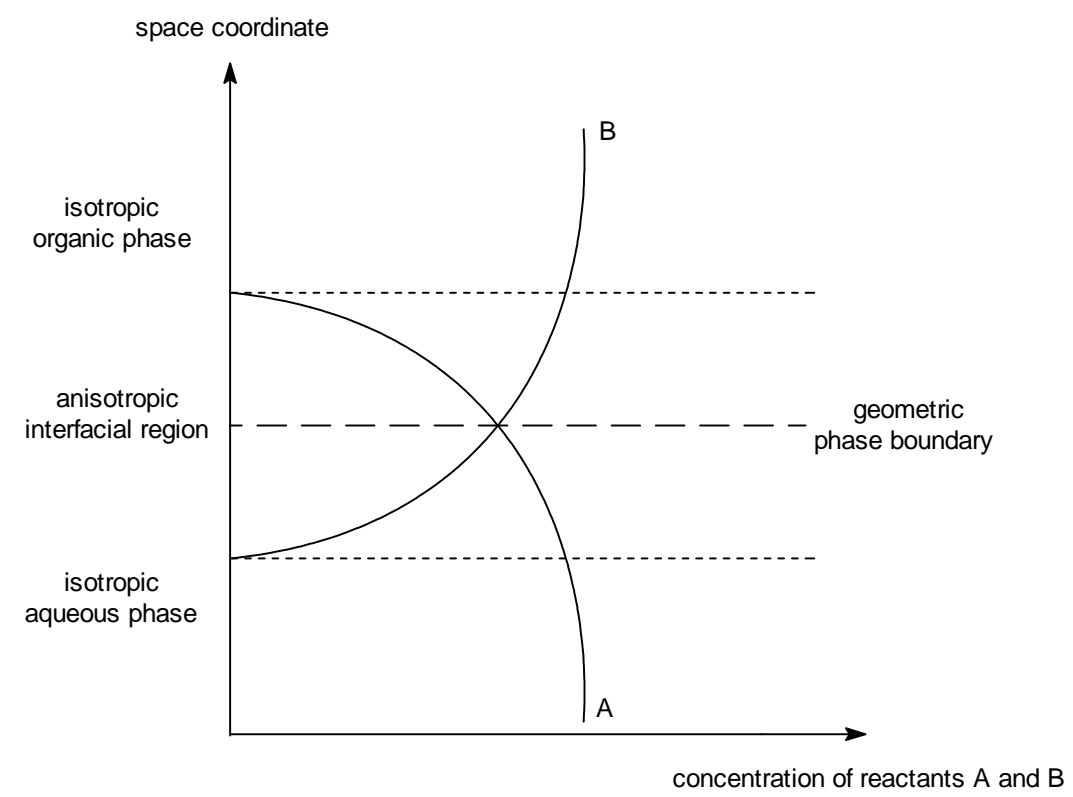

\section{Figure 1}

In the interfacial region components of different phases A and B are in contact so they can react. Since volume of this interfacial region is very small, eventual reactions between A and B proceed with negligible rate. Only when the rate constants of these reactions are very high as for instance ion-exchange or acid-base equilibrium that are essentially diffusion controlled, they do proceed in the interfacial region.

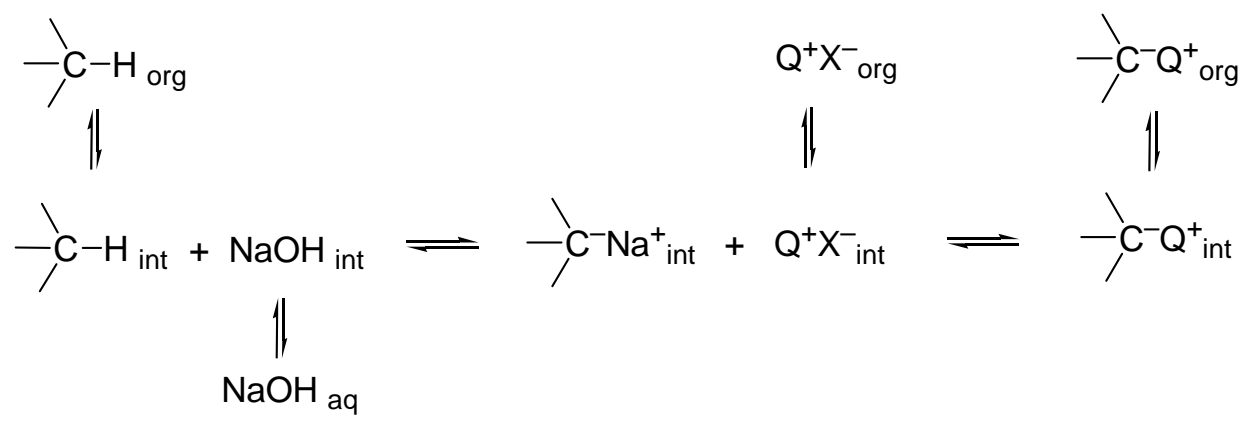

E-2 type $\beta$-elimination does not belong to this category of reactions so it requires transfer of hydroxide anions to the organic phase that is limited due to unfavourable ion-exchange equilibrium. In spite of that there are some examples of PT catalyzed $\beta$-elimination processes also in application on industrial scale.

PTC can be efficiently used for this important class of reactions when principle of cocatalysis is applied. Co-catalysis in these reactions consists in use of a third partner - a weak organic acid Y-H that in the two-phase system is deprotonated and forms lipophilic anions $\mathrm{Y}^{-}$ being weak nucleophiles and strong bases. Such anions generated at the interface are 
continuously introduced by the PT catalyst into the organic phase where they induce $\beta$ elimination of $\mathrm{HX}$ from a haloalkane producing alkene, YH and TAA salt. Deprotonation of Y-H at the phase boundary and the ion-exchange starts next co-catalytic cycle. The co-catalytic process is presented in Scheme 3.,

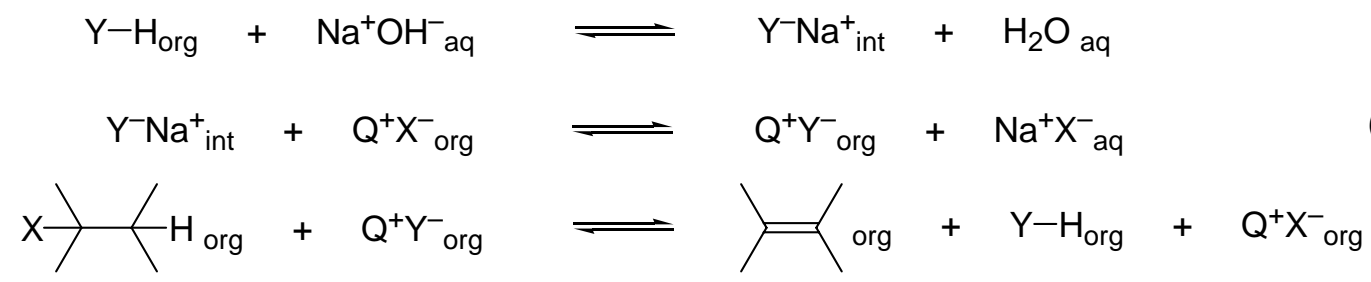

Selection of the cocatalysts $\mathrm{Y}-\mathrm{H}$ is based on following consideration: it should be rather weak acid so $\mathrm{Y}^{-}$anions would exhibit high basicity, yet sufficiently acidic to be deprotonated at the interface with aqueous $\mathrm{NaOH}$. $\mathrm{Y}^{-}$anions should be possibly weak nucleophiles so undesired nucleophilic substitution would not compete with $\beta$-elimination, and be highly lipophilic thus readily transferred into the organic phase as $\mathrm{Q}^{+} \mathrm{Y}^{-}$.

These requirements are best met by $\mathrm{OH}$ acids - alcohols and phenols. Indeed, the convenient cocatalysts were found in this group of compounds. For the model process of dehydrobromination of bromocyclohexane in the presence of $50 \% \mathrm{NaOH}$ aq and tetrabutylammonium bromide catalyst we have found that the most efficient cocatalysts are: benzhydrol, diphenyl(trifluoromethyl)carbinol, and mesitol.

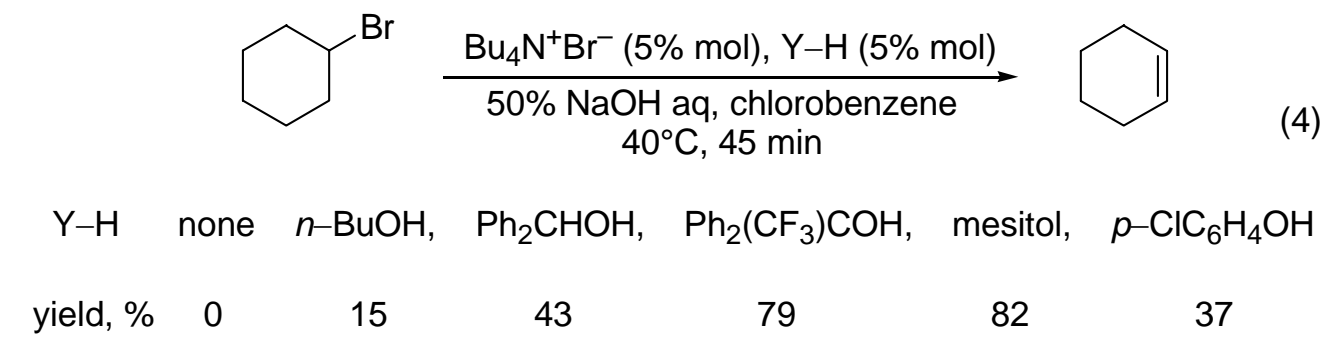

On the other hand n-butanol and phenol are much less efficient. Due to the low acidity, nbutanol is converted under these conditions into butoxide anions to a low extent, whereas due to low basicity of phenoxide anions they not induce fast elimination. ${ }^{5}$ On the basis of such consideration one can find a proper cocatalyst and conditions for particular $\beta$-elimination process. ${ }^{6}$

It should be mentioned that there are some early observations of effect of alcohols facilitating PT catalyzed $\beta$-elimination that fit excellently the concept of cocatalysis. ${ }^{7,8}$

Introduction of fluorine into an organic molecule is a process of great importance because many pharmaceuticals, plant protection agents etc. contain this atom. ${ }^{9}$ One of the general methods to achieve this goal is nucleophilic replacement of halogens or sulfonate substituents with fluoride anions. ${ }^{10}$ This reaction, although widely used, encounters difficulties due to the insolubility of 
potassium fluoride, common source of fluoride anions in majority of solvents, the high energy of hydration of fluoride anions and their high basicity so substitution process is often accompanied with $\beta$-elimination. ${ }^{10}$

High energy of hydration hence unfavourable ion-exchange equilibrium of fluoride anions makes use of typical liquid-liquid PTC a procedure of low efficiency for nucleophilic fluorination. Also liquid-solid PTC with anhydrous KF and TAA salts or crown ethers catalysts is of low effectiveness due to the low lipophilicity of fluoride anions and high energy of crystalline lattice of $\mathrm{KF} .^{11}$

These problems can be solved by the use of triphenyltin fluoride and similar compounds as cocatalysts. The cocatalytic action of triphenyltin fluoride on the fluorination process is based on the following series of events (Scheme 5). ${ }^{12}$

$$
\begin{aligned}
& \mathrm{Ph}_{3} \mathrm{SnF}_{\text {org }}+\mathrm{nKF} \text { solid } \longrightarrow \mathrm{Ph}_{3} \mathrm{SnF}_{2}{ }^{-\mathrm{K}^{+}} \mid(\mathrm{n}-1) \mathrm{KF}_{\text {solid }} \quad a \\
& \mathrm{Q}^{+} \mathrm{X}^{-}{ }_{\text {org }}+\mathrm{Ph}_{3} \mathrm{SnF}_{2}{ }^{-} \mathrm{K}^{+} \mid \mathrm{KF} \text { solid } \longrightarrow \mathrm{Ph}_{3} \mathrm{SnF}_{2}{ }^{-} \mathrm{Q}^{+} \text {org }+\mathrm{KX} \mid \mathrm{KF} \text { solid } b \\
& \mathrm{Ph}_{3} \mathrm{SnF}_{2}{ }^{-} \mathrm{Q}^{+}{ }_{\text {org }}+\mathrm{R}-\mathrm{X}_{\text {org }} \longrightarrow \mathrm{R}-\mathrm{F}+\mathrm{Ph}_{3} \mathrm{SnF}_{\text {org }}+\mathrm{Q}^{+} \mathrm{X}_{\text {org }}^{-} \mathrm{C}
\end{aligned}
$$

Reaction of triphenyltin fluoride with solid KF produces hypervalent pentacoordinate stannate anions adsorbed on solid KF that via ion-exchange form with TAA cation of the PT catalyst lipophilic ion pair entering the organic phase. The triphenyldifluorostannate anion in the organic phase reacts directly with alkyl halide or sulfonate giving expected fluoroalkane, triphenyltin fluoride and TAA salt that are ready for the next cocatalytic cycle.

Thus catalytic amounts of triphenyltin fluoride and $\mathrm{Q}^{+} \mathrm{X}^{-}$can convert large quantities of haloalkane and KF into fluoroalkane.

$$
\begin{aligned}
& \mathrm{R}-\mathrm{X}+\mathrm{KF} \quad \stackrel{\mathrm{Ph}_{3} \mathrm{SnF}\left(10 \% \mathrm{~mol}^{2}, \mathrm{Bu}_{4} \mathrm{~N}^{+} \mathrm{HSO}_{4}^{-}(10 \% \mathrm{~mol})\right.}{\mathrm{MeCN}, 85^{\circ} \mathrm{C}} \mathrm{R}-\mathrm{F} \\
& \mathrm{R}-\mathrm{X} \quad \mathrm{GC} \text { yield, } \% \\
& \mathrm{PhCH}_{2} \mathrm{Br} \sim 100 \\
& \mathrm{BrCH}_{2} \mathrm{CO}_{2} \mathrm{Et} \quad \sim 100 \\
& \mathrm{n}-\mathrm{C}_{8} \mathrm{H}_{17} \mathrm{OMs} \quad 90 \\
& \text { n- } \mathrm{C}_{6} \mathrm{H}_{13} \mathrm{CH}\left(\mathrm{CH}_{3}\right) \mathrm{OMs} \quad 82 \\
& \mathrm{CH}_{3} \mathrm{CH}(\mathrm{OMs}) \mathrm{CO}_{2} \mathrm{Et} \quad 89 \\
& \mathrm{PhSO}_{2}\left(\mathrm{CH}_{2}\right)_{3} \mathrm{OTS} \quad 82
\end{aligned}
$$

Since triphenyldifluorostannate is not a very active nucleophilic agent, the reaction $5 c$ is not a fast process and proceeds satisfactorily with active RX, e.g. benzyl bromides, alkyl mesylates etc. On the other hand this anion is also a weak base and thus fluorination of secondary mesylates proceeds efficiently in the cocatalytic system, whereas the reaction with fluoride anions results in partial or even dominant $\beta$-elimination. 
It should be mentioned that other triorganotin fluorides exert similar cocatalytic action, however their effectiveness depends on electronic effects of the substituents. The cocatalytic process embraces two distinct steps: the reaction of triorganotin fluoride with $\mathrm{KF}$ and the reaction of triorganodifluorostannate anion with $\mathrm{RX}$. In the first step $\mathrm{R}_{3} \mathrm{SnF}$ behave as a Lewis acid, so it is accelerated when $\mathrm{R}$ are electron deficient, on the other hand such $\mathrm{R}$ decrease activity of $\mathrm{R}_{3} \mathrm{SnF}_{2}^{-}$anions as donors of $\mathrm{F}^{-}$thus the substitution is decelerated (e.g. $\mathrm{R}=4-\mathrm{ClC}_{6} \mathrm{H}_{4}$ ) or totally inhibited $\left(\mathrm{R}=3-\mathrm{CF}_{3} \mathrm{C}_{6} \mathrm{H}_{4}\right)$.

$$
\begin{aligned}
& \mathrm{Ph} \widehat{\mathrm{Br}}+\mathrm{KF} \stackrel{\mathrm{R}_{3} \mathrm{SnF}(5 \% \mathrm{~mol}), \mathrm{Bu}_{4} \mathrm{~N}^{+} \mathrm{HSO}_{4}^{-}(5 \% \mathrm{~mol})}{\mathrm{MeCN}, 80^{\circ} \mathrm{C}, 24 \mathrm{~h}} \mathrm{Ph} \widehat{\mathrm{F}}_{\mathrm{F}} \\
& \mathrm{R}=3-\mathrm{CF}_{3} \mathrm{C}_{6} \mathrm{H}_{4} \quad 4-\mathrm{ClC}_{6} \mathrm{H}_{4} \quad \mathrm{C}_{6} \mathrm{H}_{5} \quad 4-\mathrm{CH}_{3} \mathrm{C}_{6} \mathrm{H}_{4} \quad \mathrm{CH}_{3} \\
& \text { conversion, \% } \quad 0 \quad 11 \quad 42 \quad 57 \quad 59
\end{aligned}
$$

Since triphenyltin chloride is a readily available and inexpensive product and reacts with KF giving triphenyltin fluoride, it can be used as efficient and inexpensive cocatalyst for PT catalyzed fluorination of alkyl halides or sulfonates.

Particularly rich field of cocatalysis is an application of PTC for transition metals catalyzed organic reactions such as carbonylation of alkyl and aryl halides, alkynes etc., Heck reaction, hydrogenation and particularly oxidation.

Carbonylation of alkyl halides in the reaction with $\mathrm{CO}$ catalyzed by $\mathrm{Co}, \mathrm{Ni}$ or Fe carbonyls leading to carboxylic acids is a reaction of great practical value. The use of PTC methodology for this reaction offers substantial advantage in terms of reaction conditions, selectivity, yields etc. Under the PTC conditions the reaction is carried out in a two-phase system in the presence of aqueous solution of $\mathrm{NaOH}$ of variable concentration. ${ }^{13}$ The organometallic catalyst, for instance dicobalt tetracarbonyl, is converted by $\mathrm{NaOH}$ into cobalt tetracarbonyl anion that is transferred into the organic phase in the form of lipophilic ion pair with TAA cation supplied by the PT catalyst. The catalytic carbonylation, namely nucleophilic substitution of the halogen with this highly nucleophilic anion resulting in the formation of $\mathrm{C}-\mathrm{Co} \sigma$ bond and the insertion of $\mathrm{CO}$ into C-Co bond, proceeds in the organic phase followed by hydrolysis of the produced acyl-cobalt derivative at the phase boundary giving sodium salt of the carboxylic acid and cobalt tetracarbonyl anion. ${ }^{14}$ The former is dissolved in the aqueous phase whereas the latter is transferred again into the organic phase by the PT catalyst so the catalytic cycle is repeated eq. 8 . 


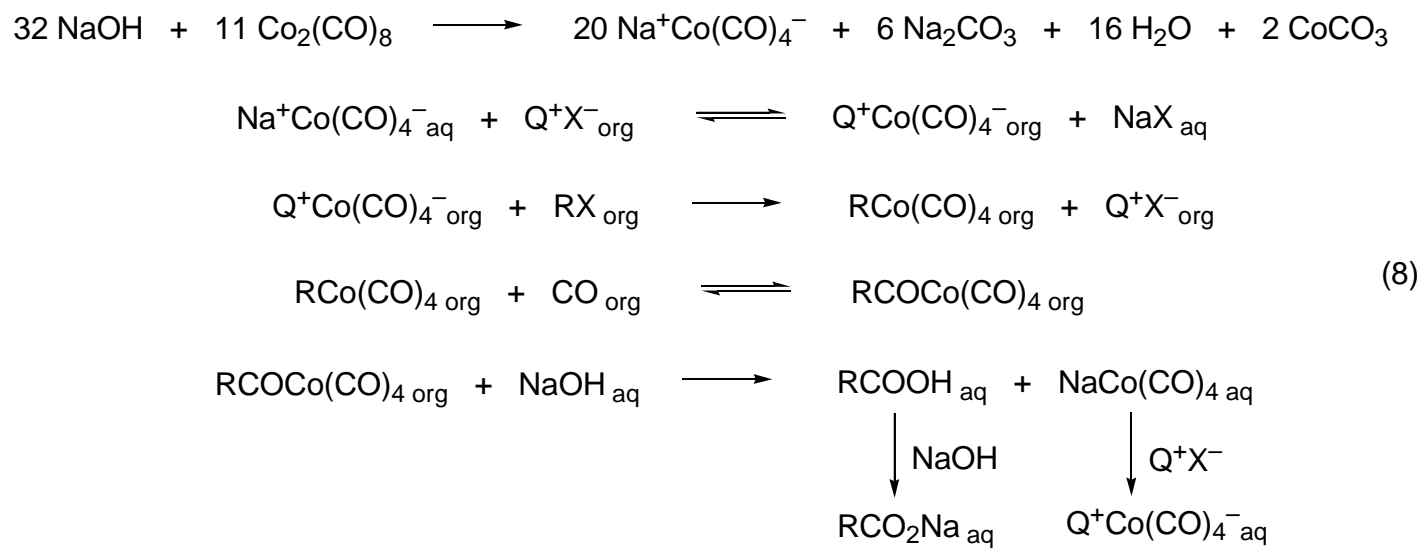

Carbonylation of benzyl halides catalyzed by cobalt carbonyls in PTC systems gave phenylacetic acid. ${ }^{15}$

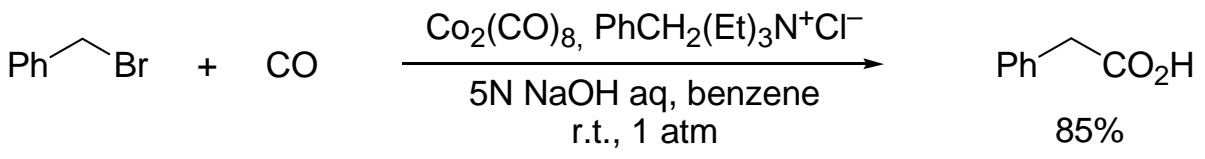

Migration of the produced carboxylic acids to the aqueous phase facilitates the carbonylation process and allows to perform selective monocarbonylation of dihalides, e.g. conversion of 1,4-dibromobenzene into 4-bromobenzoic acid. ${ }^{16}$

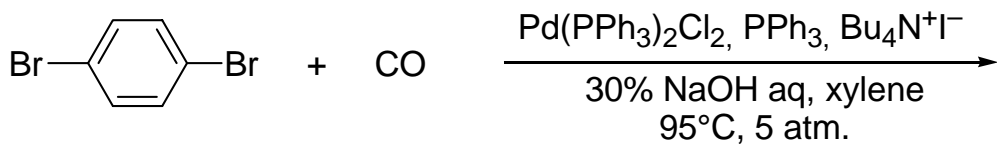

$95^{\circ} \mathrm{C}, 5 \mathrm{~atm}$.

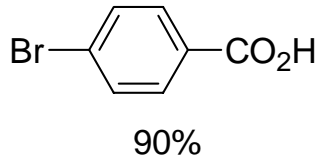

Allyl halides are efficiently carbonylated in the presence of nickel cyanide and TAA salt. ${ }^{17}$<smiles>[O-][C+]Cl</smiles>
$\frac{\mathrm{Ni}(\mathrm{CN})_{2}, \mathrm{Bu}_{4} \mathrm{~N}^{+} \mathrm{HSO}_{4}^{-}}{5 \mathrm{M} \mathrm{NaOH} \text { aq, 4-methyl-2-pentanone }}$ r.t., $1 \mathrm{~atm}$ $84 \%$

The carbonylation of acetylenes proceeds in a similar way. For example, the reaction of acetylenes with $\mathrm{CO}$ co-catalyzed by nickel cyanide and hexadecyltrimethylammonium bromide in the two-phase system: toluene - aqueous $\mathrm{NaOH}$ gave unsaturated carboxylic acids. ${ }^{18}$

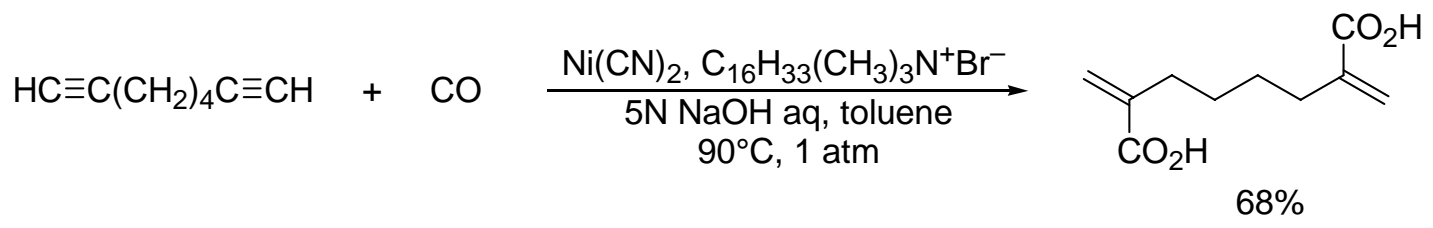


PTC has become an efficient methodology for the Heck reaction - Pd catalyzed alkenylation of aryl halides with alkenes. ${ }^{19}$ It was shown in many reports that this reaction proceeds the most efficiently when carried out in the presence of aqueous solution of sodium carbonate or hydroxide and catalytic amount of PT catalyst. ${ }^{20,21}$

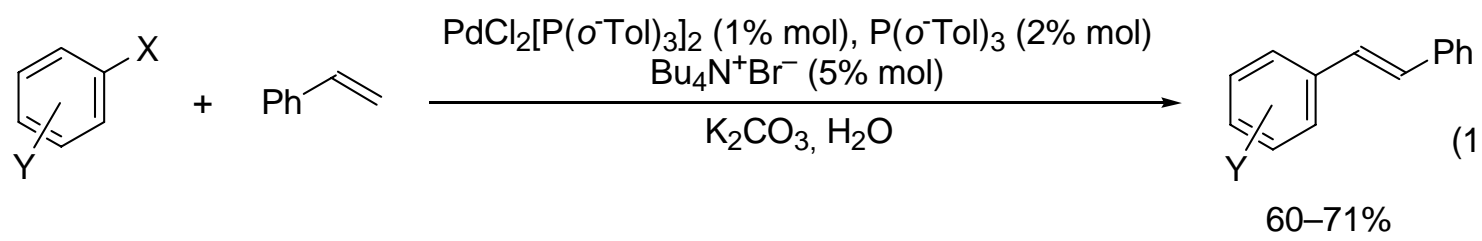

So far there has been a limited number of papers considering mechanistic rationalization of the action of PT catalyst; in our opinion suggestions that the transfer of hydroxide anions into the organic phase takes place ${ }^{21}$ is not convincing.

This methodology was extended to the Suzuki coupling of aryl bromides with arylboronic acids, however molar amounts of TAA salts are necessary to obtain high conversions. ${ }^{22}$ Recently described microwave assisted intramolecular reaction of this type, carried out under PTC conditions with catalytic amount of TAA salt, seems to be very promising. ${ }^{23}$

Of great importance are hydrogenation and reduction reactions, mediated by PT catalysts and metal carbonyls or complexes. In these two-phase reactions the TAA salt assists in the bringing together of the hydrogenation catalyst and the organic substrate. This method is particularly valuable for the hydrogenation of arenes, for which high pressures and temperatures are usually required. ${ }^{24}$
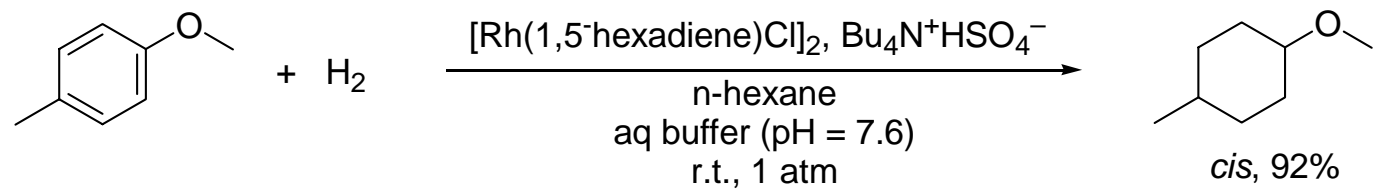

Perhaps the most important and general application of cocatalysis in PT catalyzed reactions promoted by metal derived catalysts is the oxidation of organic compounds with hydrogen peroxide. ${ }^{25}$ Combination of $\mathrm{RuCl}_{3}$ and PT catalyst serves as an excellent cocatalytic system for oxidation of alkenes and alcohols to carbonyl compounds and carboxylic acids. For instance secondary alcohols are oxidized to ketones in the presence of $\mathrm{RuCl}_{3}$ and lipophilic TAA salts in two-phase system toluene $-30 \% \mathrm{H}_{2} \mathrm{O}_{2}{ }^{26}$ The PT catalyst not only transfers $\mathrm{RuCl}_{3} \cdot \mathrm{H}_{2} \mathrm{O}_{2}$ into the organic phase but also prevents precipitation of reduced $\mathrm{Ru}$.
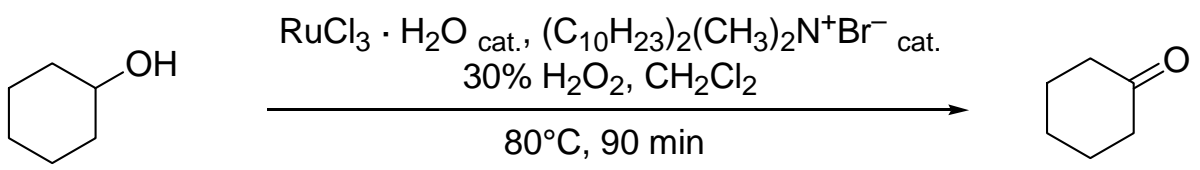
There have been many reports on the oxidation of alkenes, alcohols etc. by hydrogen peroxide catalyzed by oxygen derivatives of Mo, V, W etc. carried out in two-phase systems in the presence of PT catalysts. The most clear cut exemplification of these cocatalytic processes is the oxidation of alkenes to oxiranes and alcohols to aldehydes and acids by $30 \%$ hydrogen peroxide reported by Noyori. ${ }^{27,28}$ In this variant of PT catalyzed oxidation two catalytic processes operate consecutively. In the aqueous phase a complex of the tungstate anion with hydrogen peroxide molecule is formed and via ion exchange with TAA hydrogen sulfate is transferred into the organic phase in the form of lipophilic ion pair. In the organic phase, the metal catalyzed oxidation by this complex anion takes place with a liberation of less lipophilic complex anion containing water molecule. Ion exchange at the phase boundary brings more lipophilic complex anion containing hydrogen peroxide into the organic phase so cocatalytic process is continued (for eqs. 16 and 17 see refs. ${ }^{27,28}$ respectively).

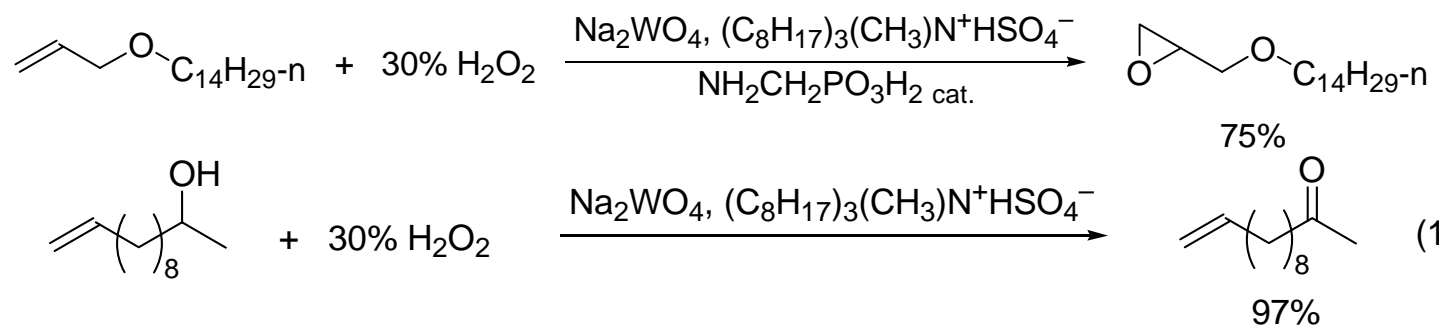

This system was applied for "green" method for the preparation of adipic acid - important industrial chemical - by direct oxidation of cyclohexene. ${ }^{29}$

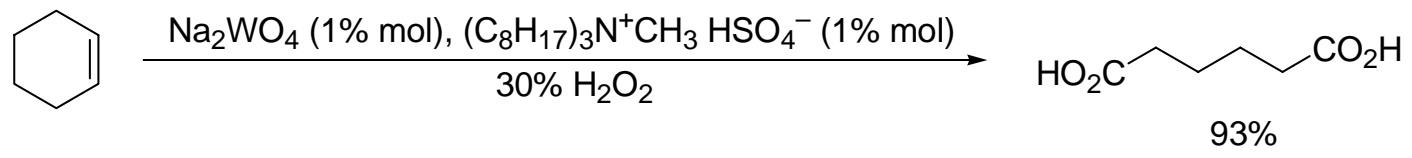

This short essay shows that effectiveness and scope of PTC can be substantially expanded by the use of a proper cocatalyst, and that combinations of PTC with a variety of metal-catalyzed reactions open wide possibilities for more efficient procedures.

\section{References}

1. (a) Dehmlow, E. V.; Dehmlow, S. S. Phase Transfer Catalysis, 3rd Ed.; VCH: Weinheim, 1993. (b) Starks, C. M.; Liotta, C. L.; Halpern, M. Phase-Transfer Catalysis. Fundamentals, Applications, and Industrial Perspectives; Chapman \& Hall: New York, 1994.

2. (a) Mąkosza, M.; Fedoryński, M. in: Interfacial Catalysis; Volkov, A. G., Ed.; Marcel Dekker: New York, Basel, 2003, pp. 159-201. Reprinted in Catalysis Rev. 2003, 45, 321367. (b) Mąkosza, M.; Fedoryński, M. in: Encyclopedia of Catalysis. Vol. 5; Horvath, I. T., Ed.; John Wiley \& Sons: Hoboken, NJ, 2003, pp. 511-564. (c) Mąkosza, M.; Fedoryński, M. Adv. in Catalysis, 1987, 35, 373. 
3. Mąkosza, M. Pure Appl. Chem. 1975, 43, 439.

4. Mąkosza, M.; Lasek, W. Tetrahedron 1991, 47, 2843.

5. Mąkosza, M.; Chesnokov, A. Tetrahedron 2000, 56, 3553.

6. Mąkosza, M.; Chesnokov, A. Tetrahedron 2002, 58, 7295.

7. (a) Shavanov, S. S.; Tolstikov, G. A.; Shutienkova, T. V.; Viktorov, G. A. Zh. Obsch. Khim. 1987, 57, 1587. (b) Shavanov, S. S.; Tolstikov, G. A.; Shutienkova, T. V.; Riabova, N. A. Zh. Org. Khim. 1989, 25, 1867.

8. Dehmlow, E. V.; Thieser, R.; Sasson, Y.; Neumann, R. Tetrahedron 1986, 42, 3569.

9. (a) Filler, R. in: Studies in Organic Chemistry, vol. 48; Filler, R., Ed.; Elsevier: New York, 1993, pp. 1-23. (b) Powell, R. L. In Methods of Organic Chemistry 4th ed., vol E10a; Houben-Weyl: 1999, Chapter 6.

10. (a) Subramanian, L.; Siegemund, R. In Methods of Organic Chemistry 4th ed., vol E10a; Houben-Weyl: 1999, Chapter A.14. (b) Wilkinson, J. A. Chem. Rev. 1992, 92, 505.

11. Dermeik, S.; Sasson, Y. J. Org. Chem. 1985, 50, 879.

12. (a) Mąkosza, M.; Bujok, R. Tetrahedron Lett. 2002, 43, 2761. (b) Mąkosza, M.; Bujok, R. J. Fluorine Chem. 2005, 126, 209.

13. For recent review on phase transfer catalysis in organometallic chemistry see: Dehmlow, E. V. In Aqueous-Phase Organometallic Catalysis: Concepts and Applications, 2nd Ed.; Cornils, B.; Herrmann, W. A., Eds.; Wiley: 2004, Chapter 4.6.1.

14. Des Abbayes, H. Israel J. Chem. 1985, 26, 243.

15. Alper, H.; des Abbayes, H. J. Organometal. Chem. 1977, 134, C11.

16. Cassar, L.; Foa, M.; Gardano, A. J. Organometal. Chem. 1976, 121, C55.

17. Joo, F.; Alper, H. Organometallics 1985, 4, 1775.

18. Amer, I.; Alper, H. J. Organometal. Chem. 1990, 383, 573.

19. For recent review on Heck reaction see: Alonso, F.; Beletskaya, I. P.; Yus, M. Tetrahedron 2005, 61, 11771.

20. Bumagin, N. A.; Bykov, V. V.; Sukhomlinova, L. I.; Tolstaya, T. P.; Beletskaya, I. P. J. Organometal. Chem. 1995, 486, 259.

21. Wang, J-X.; Liu, Z.; Hu, Y.; Wei, B.; Bai, L. Synth. Commun 2002, 32, 1607.

22. Badone, D.; Baroni, M.; Cardamone, R.; Ielmini, A.; Guzzi, U. J. Org. Chem. 1997, 62, 7170 .

23. Lepine, R.; Zhu, J. Org. Lett. 2005, 7, 2981.

24. Januszkiewicz, K. R.; Alper, H. Organometallics 1983, 2, 1055.

25. For review see: Schrader, S.; Dehmlow, E. V. Org. Prep. Proc. Int. 2000, 32, 123.

26. Barak, G.; Dakka, J.; Sasson, Y. J. Org. Chem. 1988, 53, 3553.

27. Sato, K.; Aoki, M.; Ogawa, M.; Hashimoto, T.; Panyella, D.; Noyori, R. Bull. Chem. Soc. Jpn. 1997, 70, 905.

28. Sato, K.; Aoki, M.; Tagaki, J.; Noyori, R. J. Am. Chem. Soc. 1997, 119, 12386.

29. Sato, K.; Aoki, M.; Noyori, R. Science 1998, 281, 1646. 